\title{
A implementação do Programa Nacional de Alimentação Escolar em municípios de médio e grande porte de Minas Gerais: uma abordagem institucional
}

The implementation of the National School Feeding Program in medium and large municipalities of Minas Gerais: an institutional approach

La implementación del Programa Nacional de Alimentación Escolar en municipios medianos y grandes de Minas Gerais: un enfoque institucional

Recebido: 24/07/2021 | Revisado: 01/08/2021 | Aceito: 09/08/2021 | Publicado: 14/08/2021

Isabela Renó Jorge Moreira

ORCID: https://orcid.org/0000-0002-3219-0078 Universidade Federal de Viçosa, Brasil E-mail: isareno95@gmail.com

Alair Ferreira de Freitas

ORCID: https://orcid.org/0000-0001-6770-6030 Universidade Federal de Viçosa, Brasil E-mail: alair.freitas@ufv.br

Joyce Santana Bernardo

ORCID: https://orcid.org/0000-0003-0014-8964 Universidade Federal de Viçosa, Brasil

E-mail: joycebernardoccoufv@ gmail.com

Alan Ferreira de Freitas

ORCID: https://orcid.org/0000-0002-5952-2546 Universidade Federal de Viçosa, Brasil E-mail: alanf.freitas@ufv.br

Luana Ferreira dos Santos

ORCID: https://orcid.org/0000-0002-3347-7740 Universidade Federal de Viçosa, Brasil

E-mail: luana.f.s.adm@gmail.com

Almiro Alves Júnior

ORCID: https://orcid.org/0000-0002-7130-0735 Universidade Federal de Viçosa, Brasil

E-mail: almiroalves@gmail.com

\section{Resumo}

Este estudo buscou compreender o processo operacional das compras dos produtos da agricultura familiar e suas organizações economômicas para a alimentação escolar em cinco municípios de médio e grande porte de Minas Gerais- Brasil, sendo eles: Belo Horizonte, Governador Valadares, Juiz de Fora, Montes Claros e Uberlândia. O objetivo do estudo é analisar o processo de implementação do Programa Nacional de Alimentação Escolar (PNAE) nos municípios supracitados e os dispositivos institucionais (regras e normativas) criados para operacionalizar a comercialização e a aquisição de produtos de associações e de cooperativas da agricultura familiar que particularizam e condicionam a implementação da política pública. Para tal, se utilizou de uma abordagem metodológica qualitativa, de caráter descritivo. Ainda, apesar do PNAE ser uma política pública regida por uma legislação de âmbito nacional, a Lei $n^{\circ} 11.947$ de 2009, as interações sociais e a construção de dispositivos institucionais criados nos contextos locais particularizam a implementação desta política pública. Foi possível constatar que grande parte das prefeituras, como também das associações e cooperativas da agricultura familiar tendem a criar dispositivos institucionais, sejam eles normativos e coercitivos, acordos coletivos ou até mesmo dispositivos de autorregulação que modificam o desenho institucional da operacionalização do PNAE e criam características ainda mais específicas, se comparado aos municípios que seguem somente às determinações expostas na legislação federal.

Palavras-chave: Programa nacional de alimentação escolar; Institucionalismo; Cooperativismo; Associativismo; Agricultura familiar.

\footnotetext{
Abstract

This study sought to understand the operational process of purchases of family farming products and their economic organizations for school feeding in five medium and large municipalities in Minas Gerais, Brazil, namely: Belo Horizonte, Governador Valadares, Juiz de Fora, Montes Claros and Uberlândia. The objective of the study is to analyze the process of implementation of the National School Feeding Program (PNAE) in the aforementioned municipalities and the institutional devices (rules and regulations) created to operationalize the commercialization and
} 
purchase of products from associations and cooperatives of family farming that they particularize and condition the implementation of public policy. To this end, a qualitative methodological approach was used, with a descriptive character. Still, despite the PNAE being a public policy governed by national legislation, Law No. 11,947 of 2009, social interactions and the construction of institutional devices created in local contexts particularize the implementation of this public policy. It was found that a large part of city halls, as well as family farming associations and cooperatives, tend to create institutional devices, be they normative and coercive, collective agreements or even self-regulatory devices that modify the institutional design of the operationalization of the PNAE and create characteristics even more specific, if compared to the municipalities that only follow the determinations set out in the federal legislation.

Keywords: National school feeding program; Institutionalism; Cooperatives; Associativism; Family farming.

\section{Resumen}

Este estudio buscó comprender el proceso operativo de compra de productos de la agricultura familiar y sus organizaciones económicas para la alimentación escolar en cinco municipios medianos y grandes de Minas Gerais, Brasil, a saber: Belo Horizonte, Governador Valadares, Juiz de Fora, Montes Claros y Uberlândia. El objetivo del estudio es analizar el proceso de implementación del Programa Nacional de Alimentación Escolar (PNAE) en los municipios antes mencionados y los dispositivos institucionales (normas y reglamentos) creados para operacionalizar la comercialización y compra de productos de asociaciones y cooperativas de agricultura familiar. que particularicen y condicionen la implementación de las políticas públicas. Para ello, se utilizó un enfoque metodológico cualitativo, con carácter descriptivo. Aún así, a pesar de que el PNAE es una política pública regida por la legislación nacional, la Ley $\mathrm{N}^{\circ} 11.947$ de 2009, las interacciones sociales y la construcción de dispositivos institucionales creados en contextos locales particularizan la implementación de esta política pública. Se encontró que gran parte de los ayuntamientos, así como las asociaciones y cooperativas de agricultura familiar, tienden a crear dispositivos institucionales, ya sean normativos y coercitivos, convenios colectivos o incluso dispositivos de autorregulación que modifican el diseño institucional de la operacionalización de la PNAE y crean características aún más específicas, si se comparan con los municipios que solo siguen las determinaciones establecidas en la legislación federal.

Palabras clave: Programa nacional de alimentación escolar; Institucionalismo; Cooperativismo; Asociativismo; Agricultura familiar.

\section{Introdução}

A partir dos anos 2000, com o gradativo aumento de grupos sociais lutando por direitos, floresce a necessidade de o Estado brasileiro reconhecer a diversidade social e econômica do meio rural e de superar as contradições que marcaram o período de modernização da agricultura. Nesse cenário, diferentes temas, como o acesso a mercados, foram incluídos na agenda do Estado e se tornaram políticas públicas (Grisa \& Schneider, 2014).

As transformações nas políticas públicas para o rural brasileiro foram analisadas por Grisa e Schneider (2014). Os autores procuram analisar o modo como os referenciais de políticas públicas para a agricultura familiar foram construídos. Os referenciais são ideias, ou construções conceituais elaboradas por um conjunto de atores, por meio de suas crenças e representações, que guiam a forma de compreensão dos problemas públicos. Além disso, para os autores, esses referenciais fundamentam diferentes "gerações" de políticas públicas, em uma tentativa de enquadrar, categoricamente, o grupo de políticas que resguardam formatos próprios, não pela época em que surgem, mas pelos referenciais que as criaram.

Grisa e Schneider (2014) definiram "três gerações” de políticas públicas, uma classificação criada para identificar diferentes momentos na história das políticas e novas formas de ação governamental, sendo elas: (i) referencial agrícola e agrário; (ii) referencial social e assistencialista; e (iii) referencial da construção de mercados para a segurança alimentar e sustentabilidade ambiental. A primeira geração orientava-se por um viés agrícola e agrário prevalecente na construção das bases da modernização agrícola que compreendia o problema do rural como restrito à baixa produção e à falta de tecnologia.

A segunda geração enquadrava-se na organização de ações e de políticas com caráter social e assistencial, voltadas às consequências da modernização, como a exclusão social e a notória pobreza rural. Por fim, a terceira geração de políticas públicas edificou-se na possibilidade de ampliação dos mercados, na segurança alimentar e na sustentabilidade ambiental. Nessa geração, o Estado mostrou-se mais permeável e promoveu uma virada institucional nas políticas públicas ao colocar os atores sociais como atores-chave da implementação. Essa terceira geração, mais recente no cenário das políticas para a 
agricultura familiar, possui a definidora característica de ampla articulação entre Estado e Sociedade Civil na construção das políticas ou em sua implementação (Grisa \& Schneider, 2014).

É nesse contexto de mudanças de concepções e de representações sobre o rural e a Segurança Alimentar e Nutricional (SAN) que o Programa Nacional de Alimentação Escolar (PNAE) foi modificado, em 2009, com a Lei n. ${ }^{\circ} 11.947^{1}$. Essa Lei determinou que no mínimo 30\% da verba financeira repassada pelo Fundo Nacional de Desenvolvimento da Educação (FNDE) para compra da merenda escolar seja utilizado para aquisição de gêneros alimentícios oriundos da agricultura familiar local (Oliveira; Priore \& Siqueira, 2021).

Esse processo de mudança na forma de operacionalização do PNAE pode ser compreendido como proveniente de dois elementos: primeiro, da mudança da forma de se pensar a noção de segurança alimentar e, depois, da forma de atender à reivindicação histórica da agricultura familiar pela ampliação das possibilidades de comercialização. Assim, o Estado tentou adequar uma proposta de segurança alimentar, incluindo o elemento da geração de renda por meio da ampliação dos canais de comercialização a pequenos agricultores. Apesar de ampliar as possibilidades de comercialização, conectar produção ao consumo e valorizar a SAN, as novas diretrizes do PNAE também impõem desafios para a sua efetividade em âmbito local (Oliveira; Priore \& Siqueira, 2021). Por isso, pensar o formato e os desafios na execução dessas políticas de terceira geração é uma forma de contribuir com as lacunas do campo de pesquisa e com o aprimoramento da própria política.

No PNAE, o Estado, por meio dos entes federativos estaduais e municipais, é o "comprador", o demandante dos alimentos, e os agricultores familiares, suas organizações econômicas, que acessam o Programa, são os "fornecedores", ofertantes de alimentos. De modo geral, os estados e municípios, lócus da implementação, compram produtos alimentícios e os encaminham para as entidades beneficiadas que se enquadram no Programa - escolas públicas da Educação Básica e escolas filantrópicas.

O Programa, nesse novo formato, tornou-se objeto de estudo de pesquisadores de diferentes áreas do conhecimento, que apresentam olhares divergentes, porém complementares, sobre a política pública, desde a sua contextualização e a trajetória (Peixinho, 2013; Grisa \& Schneider, 2014; Silva, 2019), sua implementação e a importância para a saúde nutricional dos estudantes (Pegolo \& Silva, 2010; Siqueira et al., 2014) e as contribuições da agricultura familiar e suas organizações coletivas como fornecedores de alimentos para o PNAE (Saraiva et al., 2013; Costa; Amorim Junior \& Silva, 2015; Silva, 2015).

Apesar do amplo espectro de trabalhos que analisam direta ou indiretamente o PNAE, constatou-se que ainda é restrito o número de pesquisas que tomaram como base empírica a implementação do programa nos grandes centros urbanos. Especificamente com ênfase em estudos envolvendo municípios de grande porte no estado de Minas Gerais, encontrou-se apenas investigações sobre a implementação do PNAE e as dificuldades para aquisição de produtos da agricultura familiar em Belo Horizonte (Silva, 2015) e em Contagem e Betim (Prado et al., 2013). Vale ressaltar que esses estudos não aprofundam nos dispositivos institucionais criados no processo de implementação do PNAE, como também não revelam a atuação de cooperativas e associações da agricultura familiar nas compras públicas.

É importante ressaltar que a dinâmica de execução do PNAE requer a compreensão de que a política pública, localmente, assume formatos singulares que não são apenas um retrato das indicações e do formato proposto pela Lei $\mathrm{n}^{\circ}$ 11.947/2009. No contexto local, a política pública é modificada e adaptada conforme a ação discricionária dos atores implementadores e de acordos e normas criados a partir da interação de diferentes atores (Bonduki, 2017; Freitas, 2017).

\footnotetext{
${ }^{1}$ Apesar do PNAE ter ganhado visibilidade com a institucionalização de uma legislação específica para compras de produtos para a alimentação escolar, a discussão da implementação de um programa governamental de alimentação escolar a nível nacional eclodiu na década de 1940, mas o debate foi inserido na agenda pública somente em 1955, aprovou-se um decreto regulamentando um programa com foco na alimentação escolar nas redes públicas de ensino. O marco institucional foi o Decreto no 37.106 de 1955, que instituiu a Campanha da Merenda Escolar (CME) (Silva, 2019).
} 
Há estudos, como os de Moura (2014); Bonduki (2017); Freitas (2017); Freitas e Freitas (2020) e Santos (2020), que se atentam à formação de dispositivos institucionais que regulam a implementação do PNAE, contudo, é necessário compreender também as regras informais e os aspectos normativos, reguladores e legitimadores, determinados em diferentes contextos de implementação do PNAE. Há ainda a lacuna de estudos científicos que inserem cooperativas e associações da agricultura familiar nesse processo de institucionalização. Essas são questões emergentes que serão discutidas neste artigo para um entendimento aprofundado sobre os atores e as instituições que colocam a política pública em prática, à luz de uma perspectiva baseada nas relações institucionais.

Considerando as questões apontadas, os principais questionamentos desta pesquisa são: (i) Como o processo de implementação do PNAE é influenciado pela interação de diferentes atores que compõem os arranjos institucionais de implementação? (ii) Quais dispositivos institucionais (regras e normativas) criados pelas prefeituras e pelas organizações da agricultura familiar particularizam e condicionam o processo de implementação do PNAE? Com essas duas questões, objetivase analisar o contexto de implementação do PNAE - em Belo Horizonte, Governador Valadares, Juiz de Fora, Montes Claros e Uberlândia - e os dispositivos institucionais criados para operacionalizar a comercialização e a aquisição de produtos de associações e de cooperativas da agricultura familiar para alimentação escolar nesses municípios de Minas Gerais. Os casos analisados foram selecionados porque representam importantes compradores de alimentos no mercado institucional de alimentos de diferentes regiões do estado, sendo essas cidades consideradas capitais regionais do estado.

Este artigo, portanto, parte de relevante base empírica, com experiências distintas de compras públicas de alimentos da agricultura familiar por meio do PNAE. Espera-se que este trabalho contribua para a reflexão sobre as particularidades locais, especialmente de cunho institucional e relacional, que influenciam o desempenho do programa e a participação de cooperativas nesse mercado.

\section{Metodologia}

Esta seção apresenta o processo de execução deste estudo, discriminando as etapas percorridas para atender os objetivos propostos e responder os questionamentos estabelecidos. Desse modo, evidencia-se as características da pesquisa, a seleção dos municípios analisados e dos atores entrevistados, o instrumento de coleta de dados e como ocorreu a organização desses dados para a realização das análises pautadas no arcabouço teórico que fundamenta este estudo.

Esta pesquisa pauta-se em uma abordagem qualitativa e de caráter descritivo, pois visa compreender o processo de operacionalização do PNAE em cinco municípios de médio e grande porte ${ }^{2}$ de Minas Gerais; uma análise embasada nos dispositivos institucionais que configuram a execução do PNAE em âmbito local. Optou-se pela pesquisa qualitativa pelo objetivo de analisar um universo de significados não quantificáveis e pela possibilidade de aprofundamento e interpretação de uma gama de assuntos e tópicos de distintas realidades sociais (Yin, 2005; Minayo, 2009).

Como pretende-se estudar a realidade de diferentes municípios mineiros, adotou-se o estudo de casos múltiplos, que possibilita identificar evidências relevantes e de maior confiabilidade se comparado aos estudos de casos únicos (Yin, 2005; Marconi \& Lakatos, 2007). O estudo com múltiplos casos viabiliza a investigação de eventos da vida real e amplia a variedade de evidências, possibilitando analisar resultados similares ou contraditórios entre os diferentes casos em estudo (Yin, 2005).

Os municípios de Minas Gerais selecionados para compor este estudo são: Belo Horizonte, Juiz de Fora e Uberlândia, considerados municípios de grande porte; Governador Valadares e Montes Claros, considerados de médio porte. A seleção desses municípios é justificada por serem considerados, pelo Instituto Brasileiro de Geografia e Estatística (IBGE, 2018),

\footnotetext{
${ }^{2}$ Neste estudo, são considerados municípios de médio porte por terem mais de 100 mil habitantes, relevância econômica local e regional e serem importantes centros para atender às demandas dos municípios próximos. Já os municípios de grande porte possuem população superior a 500 mil habitantes, são referências no acesso a serviços e às estruturas inexistentes ou deficientes em municípios menores (Stamm et al., 2013).
} 
capitais regionais, centros urbanos de referência no interior do estado, com relevância regional ou nacional.

Esses municípios são grandes demandantes de alimentos nas compras institucionais. O montante repassado ao FNDE, anualmente, para compras de produtos destinados à alimentação escolar varia entre $R$ \$ 3,2 milhões a $R$ \$ 27,2 milhões. Também se justifica estudá-los, principalmente, devido à dificuldade encontrada pela Administração Pública em adquirir, no mínimo, 30\% do orçamento dedicado à alimentação escolar em produtos advindos da agricultura familiar, e muitas Entidades Executoras (EEx) justificam que isso ocorre devido a inviabilidade de fornecimento regular e constante dos gêneros alimentício.

Para a operacionalização da pesquisa, os dados foram coletados nos cinco municípios de Minas Gerais contemplados no estudo. Os dados primários foram obtidos por meio de entrevistas, aplicadas entre os meses de agosto de 2019 e fevereiro de 2020, guiadas por roteiros semiestruturados, com representantes das organizações da agricultura familiar e com membros da Administração Pública que trabalham diretamente com a gestão do PNAE.

A população amostral foi definida pelo tipo de amostra não probabilística por acessibilidade, que não utiliza de procedimento estatístico para definição da amostra, mas sim pela facilidade de acesso aos indivíduos (Vergara, 2010). Ao todo, foram realizadas quatro entrevistas com gestores públicos e doze entrevistas com representantes de organizações coletivas da agricultura familiar (cooperativas e associações) que acessaram o PNAE nos municípios estudados entre 2015 e 2018. Para assegurar o anonimato dos entrevistados, utilizou-se codificações, conforme apresentado na Figura 1.

Figura 1. Codificação dos entrevistados.

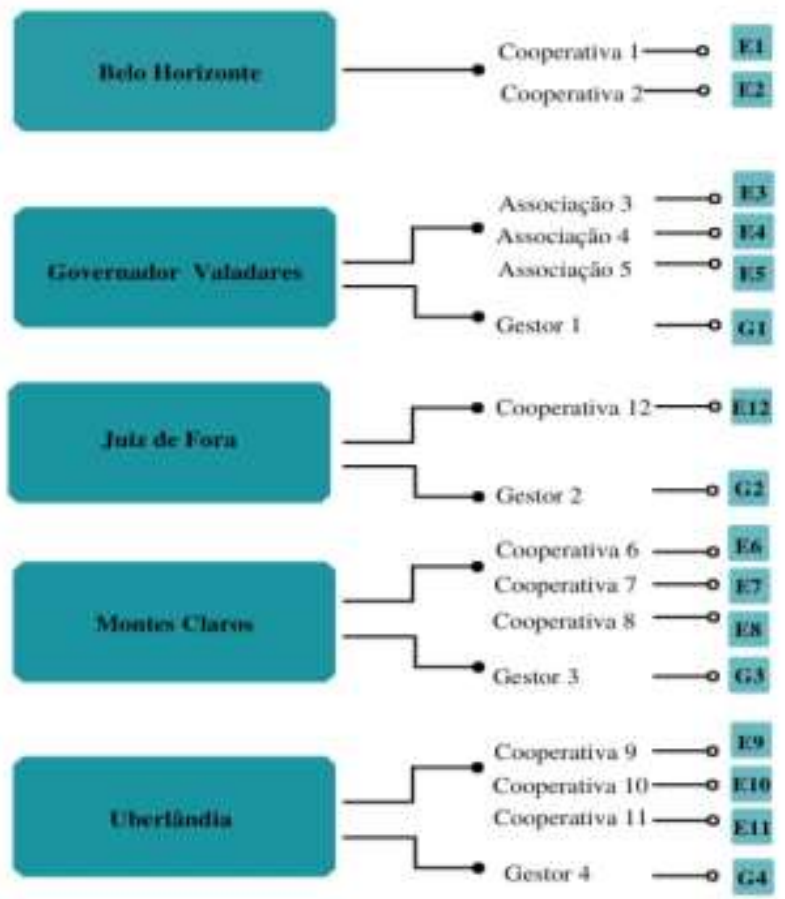

Fonte: Autores (2021).

Os dados coletados nas entrevistas foram organizados, integrando a diversidade das fontes, mas separando-os por proximidade de sentido, operando uma análise de conteúdo baseada em categorias e subcategorias definidas a priori. $\mathrm{O}$ cotejamento dos dados buscou a confrontação entre os achados da empiria com a teoria mobilizada, buscando elucidar os principais elementos que descrevem e sintetizam o fenômeno investigado. 


\section{Abordagem Institucional no Contexto do Programa Nacional de Alimentação Escolar}

Os autores da teoria institucional compreendem que as instituições são integradas por elementos normativos, coercitivos e cognitivos, e as organizações e indivíduos não se baseiam meramente em orientações pluralistas e racionalizadas. Os indivíduos, e por isso também as organizações, englobam uma série de fatores, até mesmo inconscientes, culturais, normativos, simbólicos e coercitivos, que os influenciam nas tomadas de decisões e nos seus respectivos modelos organizacionais (Carvalho; Vieira \& Lopes, 1999).

Nessa perspectiva, o que é explorado é a existência de regras e acordos que influenciam as interpretações e o modo de agir dos indivíduos e das organizações. Para March e Olsen (1984), as organizações e instituições desenvolvem papel determinante nos sistemas políticos e econômicos. Assim, o institucionalismo é o pressuposto básico de que as instituições têm importância na vida política, por meio de dispositivos formais ou informais.

Para Dimaggio e Powell (1999), as instituições não são responsáveis apenas por limitar as ações humanas e os comportamentos das organizações, são primeiro, e antes de tudo, uma produção da própria ação humana. North (1991) afirma que são as instituições que determinam as "regras do jogo", sendo responsáveis por definir as restrições que estruturam a interação humana. Os dispositivos institucionais são compostos por regras formais (leis, regulamentos, constituição); por regras informais, quando o aparato institucional não é necessariamente institucionalizado (normas de comportamento, sanções); ou por determinações culturais, que são restrições definidas e controladas pelos indivíduos da sociedade (North, 1991; Jepperson, 1999).

Schmitt (2011) explicita que, na análise das políticas públicas para a agricultura familiar, é necessária a compreensão das regras, formais e informais que construídas pelos atores para operacionalizar projetos e programas. Para a autora, os dispositivos institucionais criados são responsáveis por orientar as interações entre os atores, buscando minimizar os conflitos e garantir a estabilidade do sistema social. No âmbito de execução de uma política pública, diversos atores locais podem interagir entre si, formando parcerias, relações de confiança e cooperação. Esses elementos permitem a construção social de normas e convenções que são aceitas e legitimadas pela maioria do grupo. As normas para a interação também são estabelecidas externamente pelas diretrizes institucionais de acesso aos programas, constituindo parâmetros para a interação e, inclusive, conduzindo o modo de implementação (Freitas, 2015).

Marques (2013) considera a implementação das políticas públicas como a principal fase para a análise institucional, havendo uma expansão das fronteiras analíticas do campo de estudos referente à execução delas, dos arranjos institucionais e do exercício do Estado, o que possibilita novos entendimentos sobre os processos e as dinâmicas. Por isso, a fase de implementação da política pública não pode ser vista apenas pelos parâmetros pré-estabelecidos, mas também pelos princípios, normas e ideias que as instituições personificam (Howlett; Ramesh \& Perl, 2009).

Para Barrett (2004), compreender o processo de implementação é desvendar a dinâmica da política pública, explorar a relação das determinações políticas e as ações. Para a autora, a questão central do processo de implementação de políticas públicas é como equilibrar as exigências da responsabilidade pública, sem extrapolar os limites institucionais, mas ao mesmo tempo respeitando a discricionariedade, as diferenças e as autonomias locais (Barrett, 2004; Lipsky, 2010).

Lotta (2010) esclarece que as instituições são responsáveis por influenciar a capacidade administrativa, os recursos do Estado e a posição dos atores sociais. Para a autora, a implementação é um processo interativo e de negociações, e por isso uma questão elementar é discutir quais atores possuem influência nesse processo e quais os efeitos causados por suas participações nos resultados das políticas públicas. Conforme apontado por Barrett (2004), os implementadores das políticas estão a todo momento respondendo às pressões definidas pelo ambiente institucional.

Relacionando a perspectiva institucional com as políticas públicas de compras institucionais, especificamente o PNAE, é possível identificar que a implementação da política pública é composta por um conjunto de dispositivos 
institucionais (regras e normas, formais ou informais) que condicionam as práticas sociais dos atores. Percebe-se que diversas regras gerais (leis, decretos, resoluções) são definidas pelo Estado, no âmbito federal, principalmente determinadas pelo FNDE, classificadas por Bonduki (2017) como "padrão coercitivo".

Santos (2020), no entanto, relata que é necessário compreender também as regras e estruturas institucionalizadas na esfera federal, como também analisar as regras instituídas pelos atores envolvidos na implementação no âmbito municipal ou territorial. No PNAE, o que se percebe é que existe uma política nacional de alimentação escolar, garantida por uma legislação específica para todo o território nacional, mas com especificidades na execução. Cada município possui suas instituições relevantes, suas redes de relacionamento e de organizações essenciais que, por sua vez, modelam e determinam arranjos institucionais de execução do PNAE. Silva (2014) caracteriza esse processo como incidência territorial, resultante da adaptação das políticas públicas aos contextos socioeconômicos locais, envolvendo os arranjos institucionais locais e territoriais no ambiente de implementação.

É importante enfatizar que, na operacionalização do PNAE, as instituições atuam como mecanismos condicionantes responsáveis por reprimir ou estimular ações, ressaltando que as próprias instituições são moldadas e remodeladas pelos atores sociais envolvidos (Freitas, 2017). Dessa forma, torna-se imprescindível aprofundar em investigações empíricas que mostrem de que forma os dispositivos institucionais interferem e modificam a política pública em diferentes contextos sociais.

A própria sobrevivência e a continuidade do acesso das organizações da agricultura familiar ao PNAE estão diretamente vinculadas às determinações do ambiente institucional e regulatório, como também a configuração das redes de relacionamento. Estes fatores condicionam o funcionamento das organizações da agricultura familiar e dos mercados que por eles são acessados, muitas vezes por determinações, criação de políticas públicas, coerções formais, determinadas por normas e regras protocoladas, capazes de modificar ou coagir a ação social e econômica (Freitas, 2017).

Nesse ambiente, as organizações da agricultura familiar também criam aparatos institucionais, novas relações e negociações, como estratégia para garantir maior eficiência nas vendas para o mercado institucional ou visando facilitar o acesso ao Programa (Silva; Dias \& Amorim Junior, 2015; Freitas, 2017). Conforme apontam Silva, Dias e Amorim Junior (2015), novas regras, novas relações sociais e ações punitivas muitas vezes restringem a entrada e limitam o acesso dos agricultores familiares e suas organizações coletivas nos mercados institucionais.

Considera-se inúmeras regras e padrões construídos a partir da dinâmica de operacionalização a nível local que podem se concretizar formalmente, por meio de leis e decretos municipais, ou informalmente, consequência de crenças, símbolos, mitos, regras ou constrangimentos morais. Para Lotta (2010), de fato a implementação é um processo interativo e de negociações, por isso uma questão elementar é discutir quais os atores possuem influência nesse processo e quais efeitos são causados por suas participações nos resultados das políticas públicas. A autora critica a literatura cujo foco está nos governos durante a fase de implementação e não nos atores que de fato são os implementadores. Essa noção não cabe mais, já que a implementação das políticas públicas é consequência da construção de relações entre o Estado e a sociedade.

\section{Resultados e Discussões}

Este tópico apresenta os resultados da pesquisa, especialmente no que se refere aos processos de execução do PNAE, sob a ótica dos gestores públicos e dos representantes das cooperativas e associações, e aos dispositivos institucionais criados por prefeituras e pelas organizações para operacionalizar o PNAE nos municípios.

\subsection{Execução do PNAE: detalhes da operacionalização e das compras da agricultura familiar}

Para que as prefeituras consigam cumprir a determinação do Art. 14 da Lei n ${ }^{\circ}$ 11.947/2009 de adquirir no mínimo $30 \%$ de produtos da agricultura familiar para a alimentação escolar (Brasil, 2009), é preciso que os gestores públicos articulem 
e desenvolvam parcerias e ações para colaborar com a estrutura dos agricultores familiares, seja de forma individual ou envolvidos com alguma organização econômica da agricultura familiar (cooperativa ou associação). Desse modo, deve-se ter clareza de que o município é o ente governamental mais próximo da sociedade e o principal executor de políticas públicas, ainda que essas tenham sido elaboradas no âmbito federal ou estadual.

Os resultados desta pesquisa mostram que a gestão do PNAE em todos os municípios estudados é centralizada ${ }^{3}$, ou seja, as Entidades Executoras (EExs) centralizam as compras do Programa na esfera municipal, adquirindo os gêneros alimentícios fornecidos para preparo das refeições de todas as escolas municipais. As entregas são realizadas nas escolas ou em centros de distribuição, de acordo com o planejamento de entregas determinados pelas EExs. Apesar da centralização da gestão em todos os casos, a forma de operacionalização do Programa não é uniforme, ocorrendo de modo particular em cada município. Alguns elementos de análise que precisam ficar evidenciados são: (i) a construção de estratégias de execução do Programa, revelando se são edificados de forma coletiva ou impostas pelo governo municipal; (ii) a forma e a intensidade do envolvimento dos atores; e (iii) o processo de compra.

Os municípios selecionados possuem relevância econômica e em relação à demanda dos alimentos produzidos e comercializados no PNAE local e regional. Os volumes repassados pelo FNDE, em 2019, atingiram R \$28,417 milhões em Belo Horizonte, R \$ 7,361 milhões em Uberlândia, R \$ 4,548 milhões em Juiz de Fora e, em Governador Valadares, R \$ 4,371 milhões. Em Montes Claros, o total repassado foi apenas de R 707 mil, entretanto os gastos com a alimentação escolar foram de R \$ 4,076 milhões, uma vez que aproximadamente R \$3,668 milhões foram reprogramados do saldo de 2018 (FNDE, 2021).

As cooperativas e as associações são centrais na operacionalização do PNAE nesses municípios. Em Belo Horizonte, Governador Valadares, Juiz de Fora e Uberlândia, entre os anos de 2015 e 2018, 100\% das compras da agricultura familiar foram intermediadas por cooperativas e/ou associações. No município de Montes Claros, aproximadamente, $90 \%$ do total de recursos foi utilizado com a compra intermediada das cooperativas e associações, sendo o único município que compra produtos de agricultores familiares portadores de Declaração de Aptidão ao Pronaf (DAP). Nos municípios de Montes Claros e de Governador Valadares sobressaem as compras mediadas por associações, sendo que, entre 2015 e 2018, os percentuais de aquisições mediadas por cooperativas não ultrapassaram 24\% em Montes Claros e representaram 0\% no município de Governador Valadares. Em Belo Horizonte, em 2017, foi possível notar uma queda considerável de aquisições de cooperativas da agricultura familiar, pois, no mesmo ano, houve um aumento no número de associações dos municípios do interior de Minas Gerais acessando o mercado institucional da capital mineira.

Na Figura 2, é possível realizar um comparativo, em porcentagem, de aquisição de alimentos da agricultura familiar nos cinco municípios, entre os anos de 2015 e 2018, o que possibilita uma análise tanto comparativa, quanto individual, em relação aos percentuais de compras. É importante ressaltar que não foram considerados os volumes de recursos repassados pelo FNDE a cada município.

\footnotetext{
${ }^{3}$ A gestão do PNAE pode ser realizada de três maneiras distintas: (1) Centralizada: as Entidades Executoras do programa, no âmbito municipal, adquirem os gêneros alimentícios fornecidos para preparo das refeições de todas as escolas municipais. As entregas são realizadas nas próprias escolas ou em centros de distribuição de acordo com o planejamento de entregas por estabelecimento escolar; (2) Descentralizada: também conhecida como "escolarizada", ocorre em casos em que os próprios gestores escolares adquirem os produtos e gerenciam o programa; (3). Semidescentralizada: quando há uma combinação entre a gestão centralizada e a descentralizada (FNDE, 2021).
} 
Figura 2. Comparativo em porcentagem de aquisição de alimentos da agricultura familiar.

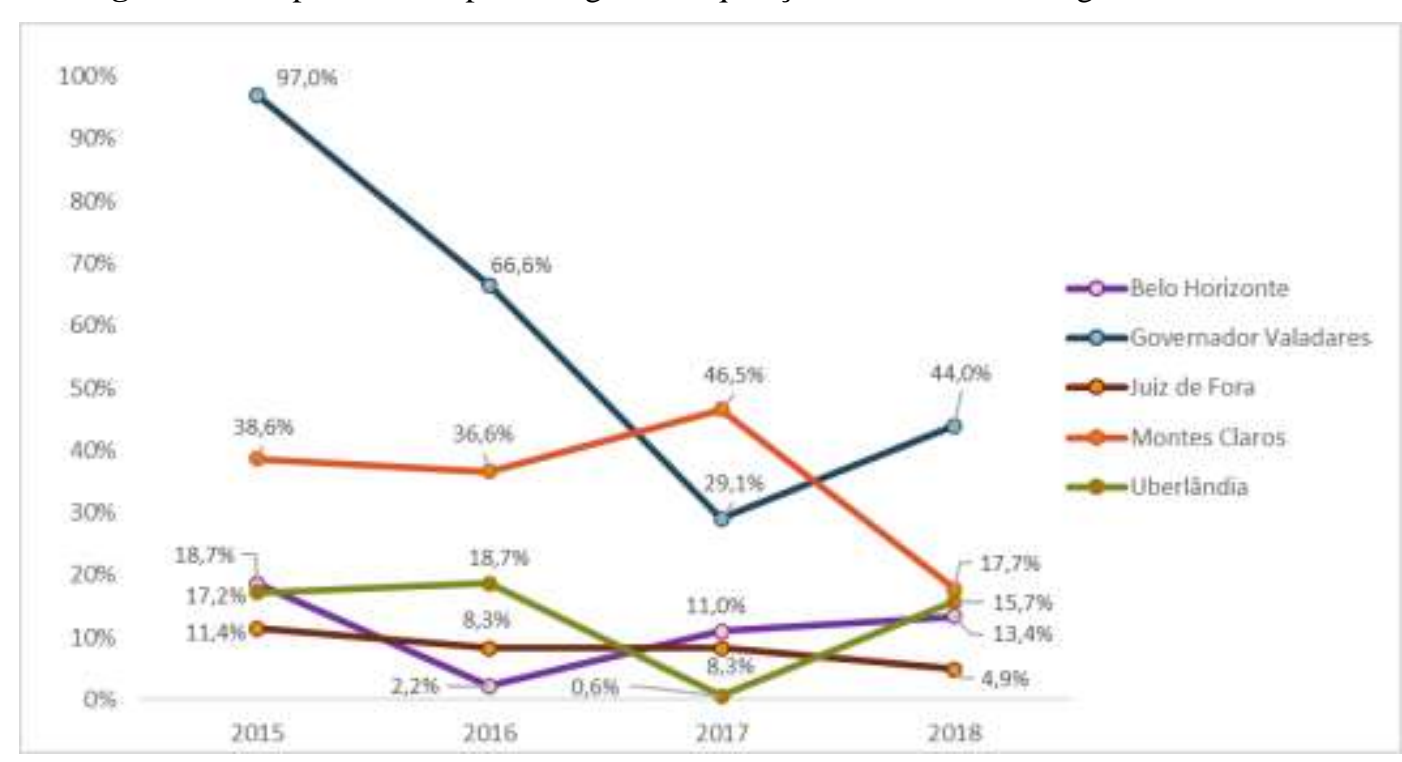

Fonte: Autores, com base em Sistema de Gestão de Prestação de Contas do FNDE - SIGPc (FNDE, 2021).

Em análise individual, observa-se que, em Belo Horizonte, a maior porcentagem de aquisições de produtos da agricultura familiar ocorreu no ano de 2015, representando aproximadamente 19\% (R \$ 6.318.152,34). Entretanto, em 2016, houve queda significativa desse percentual, com aquisição de apenas 2,2\% (R \$ 561.119,88), resultando no menor volume de aquisições da agricultura familiar nos anos estudados.

No município de Governador Valadares, o ano em destaque é 2015, pois foram adquiridos cerca de $97 \%$ da agricultura familiar em relação aos recursos totais transferidos via FNDE, representando $\mathrm{R} \$ 3.564 .650$,28. Por fim, em 2017, adquiriu-se apenas R $\$ 1.339 .809,89$, menor volume entre 2015 e 2018, justificado, pelo Gestor 1, devido à dificuldade das associações do município em realizar as entregas dos produtos que foram solicitados na Chamada Pública.

Em Juiz de Fora, o patamar de aquisições da agricultura familiar alcançou o percentual máximo de 11,4\% ( $\mathrm{R} \$ 465.855,83$ ) em 2015 e houve queda expressiva em 2018, com apenas 4,9\% de recursos financeiros destinados, o que totaliza $\mathrm{R} \$ 225.038,94$. Juiz de Fora é o município que apresentou menores volumes de aquisição de produtos da agricultura familiar.

Já em Montes Claros, 2017 foi o ano de destaque do percentual de aquisições, que atingiu 46,5\% (R $\$ 1.504 .309,83$ ), indicando a atenção e o direcionamento da gestão municipal em adquirir e fornecer alimentos da agricultura familiar para a alimentação escolar. Os gestores públicos de Montes Claros mantiveram, em 2018, uma destinação de recursos financeiros nominais semelhante ao ano anterior, de $\mathrm{R} \$ 1.654 .912,95$. Contudo, quando confrontado com o montante total repassado pelo FNDE em 2018, esse valor correspondeu a 86,68\%, resultado da utilização do saldo anterior de 2017 na composição das despesas de 2018, além de redução da transferência recebida pelo FNDE. Portanto, o expressivo aumento no percentual de 2018 não se deve ao acréscimo de recursos destinados à agricultura familiar.

Por fim, no município de Uberlândia, tanto em 2015, como em 2016, adquiriu-se 18,7\% de produtos da agricultura familiar, em relação ao total repassado pelo FNDE. Um fato importante que merece destaque é a dificuldade do município em adquirir alimentos no ano de 2017 , tendo como consequência a compra de apenas $R \$ 39.785,25$, aproximadamente $0,6 \%$, oriundos da agricultura familiar, decorrentes de adversidades nos editais da Chamada Pública, conforme exposto pelo gestor público local. No ano de 2018, mesmo com melhorias em relação à situação do ano anterior, não foi possível atingir o mínimo de 30\%, visto que a aquisição representou $\mathrm{R} \$ 1.119 .134,68$, isto é, $15,7 \%$ do montante total transferido pelo FNDE.

Em síntese, nos anos analisados, somente Governador Valadares e Montes Claros ultrapassaram 30\%, com exceção 
dos anos de 2017, em Governador Valadares, e de 2015, em Montes Claros. O município de Belo Horizonte não atingiu os $30 \%$, Uberlândia não chegou a $20 \%$ e Juiz de Fora não ultrapassou $12 \%$, em nenhum dos anos observados, sendo esse último o município com a situação mais agravante, pois adquiriu produtos de apenas uma organização da agricultura familiar em todos os anos analisados. O que se percebe é um grande potencial de compras da agricultura familiar ainda a ser atingido nos municípios que não adquirem o mínimo exigido pela Lei n. ${ }^{\circ}$ 11.947/2009, comprovando o que Silva (2015) afirmou sobre apenas o direito de venda, definido pela prerrogativa da Lei, não garantir a comercialização, caso não se crie provimentos que viabilizem o acesso da agricultura familiar.

Os dados das aquisições de alimentos no âmbito do PNAE indicam que os diferentes resultados percentuais podem estar diretamente relacionados com a composição de atores que participaram dos processos de produção e de compra dos produtos, bem como das instituições que regularam as ações na operacionalização. A dificuldade em adquirir e comercializar o mínimo exigido pode partir das próprias organizações, por exemplo, ao ofertar os alimentos atendendo a quantidades necessárias e às exigências burocráticas e sanitárias, como também pode ser uma dificuldade da Administração Pública em inserir a agricultura familiar como fornecedora de produtos, seja por dificuldade de diálogo, seja pela adequação dos preços ou dos cardápios à realidade socioprodutiva local.

Em relação ao processo de compra dos produtos, notou-se que, apesar da maioria dos municípios seguirem etapas similares no processo de compra, existem diferenciações dentro de cada etapa que modificam a operacionalização. As etapas apontadas em grande parte das entrevistas são representadas na Figura 3. No caso da primeira etapa, o contato diretamente com as cooperativas e associações fica mais evidente em Uberlândia e Montes Claros.

Figura 3. Etapas de implementação das compras da agricultura familiar no PNAE.

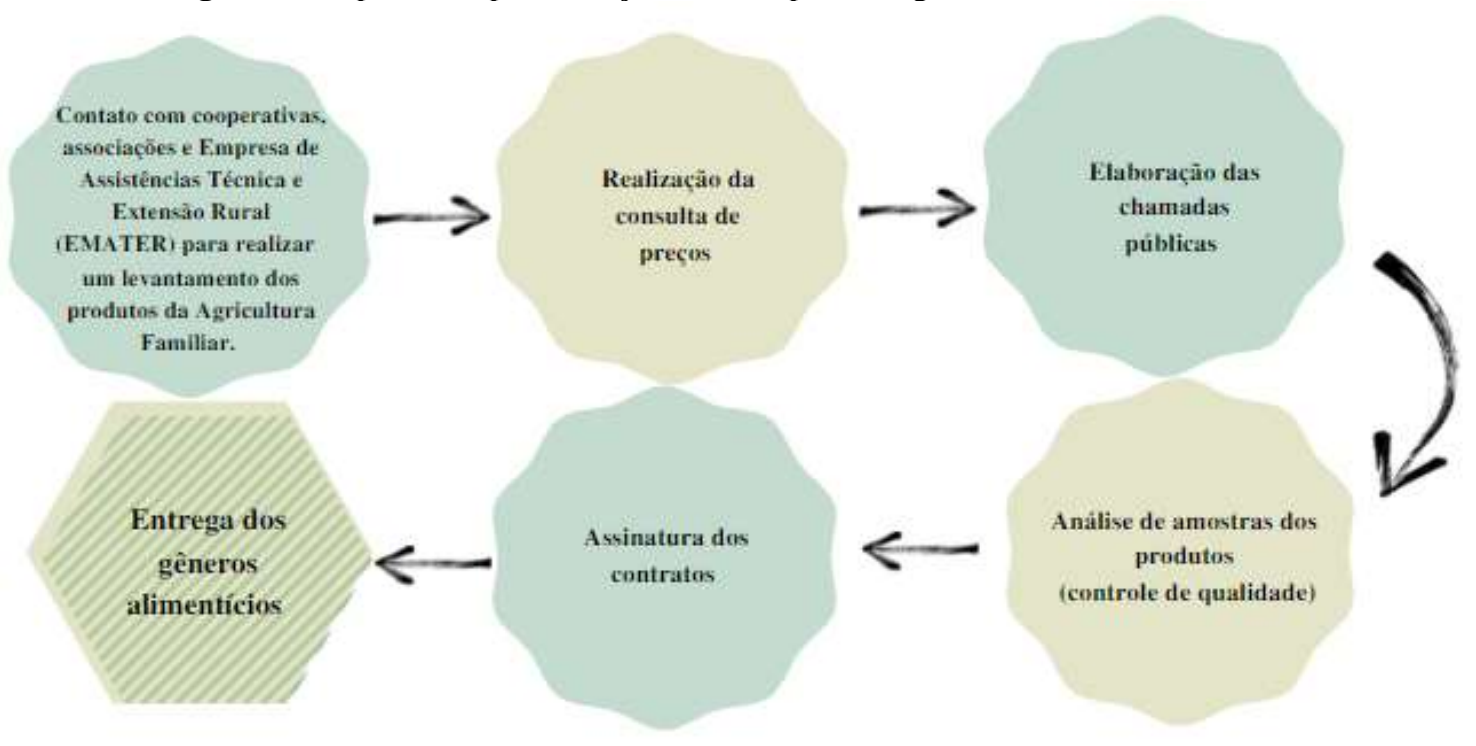

Fonte: Autores (2021).

A primeira etapa de implementação, evidenciada nos municípios de Belo Horizonte, Uberlândia e Montes Claros, relaciona-se às compras da agricultura familiar e ocorre quando a EEx entra em contato com as organizações ou com a Empresa de Assistência Técnica e Extensão Rural (EMATER) com o objetivo de pesquisar os produtos comercializados pela agricultura familiar e o calendário de produção agrícola. A segunda etapa é representada pela consulta dos preços praticados nos mercados para os produtos a serem solicitados nas Chamadas Públicas. Nesses casos, o contato tem como objetivo a realização de uma consulta dos produtos que podem ser ofertados, visando construir os cardápios, de acordo com os produtos que respeitam o calendário agrícola e a cultura alimentar local, embasado no $9^{\circ}$ princípio (Diversidade de Cenários de Prática) 
da Educação Alimentar e Nutricional (EAN)4.

A consulta pode envolver os preços praticados em sacolões, mercados, feiras da agricultura familiar ou nas vendas diretas das cooperativas e associações. Após a primeira e segunda etapas, são elaboradas e divulgadas as Chamadas Públicas, procedimento que dispensa as licitações. Nessas Chamadas, devem constar as informações de todo o processo de aquisição, como documentações necessárias, produtos solicitados, quantitativos, preços, obrigações e responsabilidades dos fornecedores. Em alguns casos, a prefeitura pode solicitar às organizações ou aos agricultores familiares, cujos projetos de vendas foram comtemplados, amostras dos produtos para realizar o controle de qualidade, antes da assinatura dos contratos - a quinta etapa. A última etapa é a entrega dos gêneros alimentícios, seja diretamente nas escolas ou em centros de distribuição das prefeituras.

Apesar da categorização em etapas apontadas nas entrevistas e demonstradas anteriormente, localmente, os processos de implementação da política pública são particularizados e divergem de acordo com o nível de engajamento da gestão pública municipal e dos agricultores familiares e com o grau de institucionalização. Para iniciar as discussões quanto às particularidades de operacionalização, apresenta-se o Quadro 1, com comparativos de aspectos, como processos logísticos de entrega e distribuição, a quantidade de itens adquiridos da agricultura familiar por municípios, a pesquisa dos preços praticados nesse mercado, e as contribuições das cooperativas e associações específicas em cada caso.

\footnotetext{
${ }^{4}$ Segundo o Marco de Referência de Educação Alimentar e Nutricional para as Políticas Públicas os nove princípios para nortear as práticas de EAN são: 1. Sustentabilidade social, ambiental e econômica; 2. Abordagem do sistema alimentar, na sua integralidade; 3 . Valorização da cultura alimentar local e respeito à diversidade de opiniões e perspectivas, considerando a legitimidade dos saberes de diferentes naturezas; 4 . A comida e o alimento como referências; Valorização da culinária enquanto prática emancipatória; 5. A Promoção do autocuidado e da autonomia; 6. A Educação enquanto processo permanente e gerador de autonomia e participação ativa e informada dos sujeitos; 7. A diversidade nos cenários de prática; 8. Intersetorialidade; e 9. Planejamento, avaliação e monitoramento das ações (Brasil, 2021).
} 
Quadro 1. Aspectos da implementação por município.

\begin{tabular}{|c|c|c|c|c|c|}
\hline Municípios & Belo Horizonte & $\begin{array}{l}\text { Governador } \\
\text { Valadares }\end{array}$ & Juiz de Fora & Montes Claros & Uberlândia \\
\hline $\begin{array}{l}\text { Logística de } \\
\text { distribuição e } \\
\text { entrega }\end{array}$ & $\begin{array}{l}\text { Cooperativas } \\
\text { realizam as entregas } \\
\text { nos centros de } \\
\text { distribuição da } \\
\text { prefeitura e a } \\
\text { prefeitura se } \\
\text { responsabiliza pela } \\
\text { entrega nas escolas. }\end{array}$ & $\begin{array}{l}\text { Prefeitura se } \\
\text { responsabiliza por } \\
\text { todo processo de } \\
\text { distribuição e } \\
\text { entrega dos } \\
\text { produtos. }\end{array}$ & $\begin{array}{l}\text { Cooperativa } \\
\text { realizam as entregas } \\
\text { diretamente nas } \\
\text { escolas. }\end{array}$ & $\begin{array}{l}\text { Grande parte dos } \\
\text { produtos são } \\
\text { entregues pelas } \\
\text { associações e } \\
\text { cooperativas nos } \\
\text { centros de } \\
\text { distribuição e a } \\
\text { prefeitura se } \\
\text { responsabiliza pela } \\
\text { entrega nas escolas. }\end{array}$ & $\begin{array}{l}\text { Os produtos in natura } \\
\text { são entregues pelas } \\
\text { cooperativas nos centros } \\
\text { de distribuição e a } \\
\text { prefeitura se } \\
\text { responsabiliza pela } \\
\text { entrega nas escolas. }\end{array}$ \\
\hline Definição de preços & $\begin{array}{c}\text { A empresa } \\
\text { terceirizada realiza } \\
\text { cotações de preço } \\
\text { em mercados } \\
\text { atacadistas, podendo } \\
\text { não considerar os } \\
\text { preços praticados } \\
\text { pela agricultura } \\
\text { familiar. }\end{array}$ & $\begin{array}{c}\text { Pesquisa de preço } \\
\text { em três mercados } \\
\text { locais (sacolões e } \\
\text { supermercados). } \\
\text { Para as associações } \\
\text { o preço é } \\
\text { considerado } \\
\text { insatisfatório. }\end{array}$ & $\begin{array}{l}\text { Na chamada pública } \\
\text { não esclarece o } \\
\text { método de definição } \\
\text { dos preços, o que é } \\
\text { questionado pela } \\
\text { cooperativa local. }\end{array}$ & $\begin{array}{l}\text { A cotação é baseada } \\
\text { nos preços de } \\
\text { referência da } \\
\text { Companhia Nacional } \\
\text { de Abastecimento } \\
\text { (CONAB). }\end{array}$ & $\begin{array}{l}\text { Média de preço } \\
\text { praticado em } \\
\text { supermercados, } \\
\text { sacolões, Ceasa, feiras } \\
\text { livres e cooperativas. }\end{array}$ \\
\hline $\begin{array}{c}\text { Produtos } \\
\text { adquiridos das } \\
\text { cooperativas e } \\
\text { associações }\end{array}$ & $\begin{array}{l}\text { Leite em pó, café, } \\
\text { feijão, carnes, arroz, } \\
\text { frutas e legumes in } \\
\text { natura. }\end{array}$ & $\begin{array}{l}\text { Frutas e legumes in } \\
\text { natura, folhosos, } \\
\text { polpas e doces de } \\
\text { frutas e panificados. }\end{array}$ & Mel. & $\begin{array}{c}\text { Frutas e legumes in } \\
\text { natura, folhosos, } \\
\text { polpas de frutas e } \\
\text { mel. }\end{array}$ & $\begin{array}{l}\text { Frutas e legumes in } \\
\text { natura e minimamente } \\
\text { processados, folhosos, } \\
\text { farinhas, feijão e mel. }\end{array}$ \\
\hline $\begin{array}{l}\text { Participação das } \\
\text { cooperativas e } \\
\text { associações da } \\
\text { agricultura } \\
\text { familiar na } \\
\text { operacionalização }\end{array}$ & $\begin{array}{l}\text { Participam da } \\
\text { consulta semanal } \\
\text { realizada pelas } \\
\text { nutricionistas } \\
\text { responsáveis } \\
\text { técnicas a fim de } \\
\text { levantar as } \\
\text { quantidades e os } \\
\text { produtos } \\
\text { disponíveis. }\end{array}$ & $\begin{array}{l}\text { Não foi mencionado } \\
\text { a participação das } \\
\text { associações na } \\
\text { construção das } \\
\text { chamadas públicas e } \\
\text { a consulta de preços. }\end{array}$ & $\begin{array}{l}\text { Não foi mencionado } \\
\text { a participação da } \\
\text { cooperativa na } \\
\text { construção das } \\
\text { chamadas públicas e } \\
\text { a consulta de preços. }\end{array}$ & $\begin{array}{l}\text { As nutricionistas } \\
\text { responsáveis } \\
\text { técnicas entram em } \\
\text { contato para realizar } \\
\text { consulta de produtos } \\
\text { para construir } \\
\text { cardápios e } \\
\text { chamadas públicas } \\
\text { que respeitem o } \\
\text { calendário agrícola e } \\
\text { a cultura alimentar. }\end{array}$ & $\begin{array}{c}\text { Contribuição das } \\
\text { cooperativas na } \\
\text { construção das } \\
\text { chamadas públicas com } \\
\text { base no calendário } \\
\text { agrícola e na consulta } \\
\text { dos preços. }\end{array}$ \\
\hline
\end{tabular}

Fonte: Autores, com base em FNDE (2021) e dados da pesquisa.

As particularidades apresentadas em cada município são resultantes da construção social da política pública em diferentes contextos, nos quais a participação das próprias cooperativas e associações na implementação pode influenciar seu desempenho. Os dispositivos institucionais criados e as relações sociais estabelecidas são aspectos norteadores que modelam a implementação do PNAE nos municípios.

Apesar de haver a determinação das compras da agricultura familiar, por meio da política pública no âmbito nacional, principalmente fundamentada pela Lei n. ${ }^{\circ}$ 11.947/2009, depois complementada por Resoluções do FNDE, e seguindo as mesmas etapas de execução, na maioria dos casos, cada município apresenta singularidades e determina dispositivos institucionais, no contexto local e territorial, que particularizam a operacionalização e, consequentemente, os resultados da Política Pública, conforme apontam Silva (2014), Bonduki (2017) e Santos (2020).

\subsection{Dispositivos institucionais e implementação do PNAE nos municípios}

$\mathrm{Na}$ ótica institucional, o processo de implementação de uma Política Pública deve ser baseado na relação existente entre os seus atores locais, respeitando as regras pré-estabelecidas e criando dispositivos institucionais para adequar a normatização à prática cotidiana (Freitas \& Freitas, 2020). Dentre os principais dispositivos institucionais nos municípios 
estudados, notou-se uma diferenciação da atuação e do protagonismo de algumas secretarias na execução do PNAE, pois, em alguns casos, é marcante a intersetorialidade e, em outros, a atuação é focada principalmente em uma única secretaria. Além disso, é variante também o relacionamento dos indivíduos-chave da agricultura familiar com suas organizações coletivas.

Sistematicamente, em relação às regras e aos acordos presentes nos municípios, foi possível constatar três principais níveis analíticos de institucionalizações envolvidas na operacionalização do PNAE nos municípios. Conforme sumarizado no Quadro 2, pode-se denominar tipologias de dispositivos institucionais na execução do PNAE: (i) dispositivos normativos e coercitivos; (ii) acordos coletivos; e (iii) autorregulação das cooperativas e associações.

Quadro 2. Tipologias de dispositivos institucionais na execução do PNAE

\begin{tabular}{|c|c|c|}
\hline Tipologias & Características & $\begin{array}{c}\text { Exemplos de dispositivos } \\
\text { institucionalizados }\end{array}$ \\
\hline $\begin{array}{c}\text { Dispositivos normativos e } \\
\text { coercitivos }\end{array}$ & $\begin{array}{c}\text { Majoritariamente determinações formais } \\
\text { institucionalizadas pelas prefeituras. }\end{array}$ & $\begin{array}{c}\text { Decretos municipais que regulamentam o } \\
\text { PNAE a nível municipal. }\end{array}$ \\
\hline $\begin{array}{c}\text { Autorregulação das cooperativas e } \\
\text { associações }\end{array}$ & $\begin{array}{c}\text { Regras institucionalizadas pelas próprias } \\
\text { organizações da agricultura familiar. }\end{array}$ & $\begin{array}{c}\text { Acordos determinados pelas cooperativas e } \\
\text { associações para participação nas chamadas } \\
\text { públicas. }\end{array}$ \\
\hline Acordos coletivos & Regras informais criadas pelas \\
cooperativas & $\begin{array}{c}\text { Regras criadas pela diretoria das } \\
\text { cooperativas, compartilhadas e aceitas pelos } \\
\text { cooperados visando facilitar o acesso ao } \\
\text { PNAE }\end{array}$ \\
\hline
\end{tabular}

Fonte: Autores (2021).

Os dispositivos normativos e coercitivos referem-se às determinações das prefeituras, em geral formalizadas, definidas por normas e coerções impostas a todos os atores da rede de implementação. Por sua vez, a autorregulação das cooperativas e associações refere-se a dispositivos institucionais resultantes das construções sociais, definidos pelas próprias organizações, com o objetivo de disciplinar a participação da agricultura familiar no PNAE, exigindo relações de confiança e de proximidade entre os representantes das cooperativas e associações para se criar mecanismos de autorregulação. Por fim, os acordos coletivos são regras informais criadas pelas cooperativas e compartilhadas com os seus cooperados, sendo determinações que exigem algum grau de confiança e de relacionamentos interpessoais.

Analisando os dispositivos normativos e coercitivos da Política Pública, notou-se que um dos principais dispositivos são as Chamadas Públicas construídas pelas EExs. O objetivo dessas Chamadas é divulgar o edital que contém detalhes e informações do processo de aquisição dos produtos da agricultura familiar. Nesse edital, divulgado anualmente ou semestralmente, a depender do município, são apresentadas as regras e os documentos necessários para participação no Programa, os preços, as quantidades, as exigências sanitárias dos produtos e o detalhamento da logística de entrega.

Uma das regras, institucionalizada nas Chamadas Públicas dos municípios de Belo Horizonte e Governador Valadares, determina que as compras via Chamada Pública somente poderão ser realizadas por intermédio dos Grupos Formais e dos empreendimentos familiares constituídos de cooperativas e associações detentoras de DAP Jurídica, com documentação regular, embasado no Art. 30 da Resolução CD/FNDE n. ${ }^{\circ}$ 26, de 2013 (Brasil, 2013). Em Juiz de Fora, além dos grupos formais, podem participar os grupos informais, enquanto em Montes Claros e Uberlândia, os fornecedores individuais, detentores de DAP Física, também estão aptos a participar das Chamadas Públicas.

Outro dispositivo normativo, estabelecido formalmente por meio de decretos, está relacionado à determinação das competências e atribuições das secretarias municipais responsáveis pela execução do PNAE. Em Montes Claros, a Secretaria de Educação, mediante a Coordenadoria de Nutrição e Segurança Alimentar, é a principal responsável pela coordenação de todas as etapas da execução do PNAE no município, desde o planejamento da compra, alinhado com as nutricionistas e com os produtores, até o encaminhamento das notas para pagamento no setor financeiro da prefeitura. Com o apoio da EMATER, a 
Secretaria de Educação também realiza um planejamento produtivo para as compras da agricultura familiar, respeitando o calendário das safras.

No município de Juiz de Fora, segundo o Gestor Público 2, a Secretaria Municipal de Educação e a Secretaria de Desenvolvimento Econômico, Turismo e Agropecuária (SEDETA) exercem as ações de implementação do PNAE, de maneira conjunta, para atender aproximadamente 37 mil alunos. As atribuições são divididas entre a Secretaria de Educação, que coordena o Programa nas escolas, e a SEDETA, que é a principal responsável por conferir os produtos, entrar em contato com a cooperativa, fiscalizar a execução e realizar os pagamentos. Apesar do entrevistado G2 afirmar que as secretarias, junto a EMATER, realizam uma leitura de produção agrícola do território, tal fato não foi confirmado pelo entrevistado C12, e ainda são irrisórios os volumes de compra da agricultura familiar.

Em Governador Valadares, a Secretaria de Educação tem participação expressiva na execução, com a responsabilidade de elaborar cardápios e acompanhar a execução do Programa nas escolas, e a Secretaria de Meio Ambiente, Agricultura e Abastecimento (SEMA), junto às associações que comercializam para o PNAE, atua como um caminho condutor para que as cooperativas consigam atender às demandas do Programa. Nesse município, as associações não são responsáveis pela elaboração dos projetos de venda, uma vez que esses são elaborados pela SEMA.

Nesse caso, o processo de compra e venda de produtos das associações é centralizado principalmente na SEMA, enquadrando-se em um modelo de implementação tutelada, no qual a Administração Pública estabelece as determinações do Programa, sem a participação de outros atores sociais, principalmente do público fornecedor de gêneros alimentícios. Apesar de existir o contato entre as secretarias e os agricultores familiares, as relações são direcionadas mais ao apoio logístico e à gestão dos empreendimentos.

O apoio logístico ocorre principalmente por meio da disponibilização de um caminhão para o recolhimento dos produtos das associações uma vez por semana. Entretanto, segundo os entrevistados das associações A3, A4 e A5 os preços pagos pela prefeitura no PNAE são menores, com a justificativa de que é descontado o preço do frete. Conforme relatado pelo entrevistado E5, falta organização e apoio por parte do poder público, que realiza determinações sem a participação de representantes das organizações. Para ele, "é absurdo [...] o produtor tem o direito de saber o valor que colocam no seu produto" (Entrevistado E5, 2019).

O representante da Cooperativa 12 relata que o preço dos produtos em Juiz de Fora também é determinado sem a participação dos atores da agricultura familiar. Para o entrevistado E12, a prefeitura "é nula e omissa", evidenciando a falta de diálogo entre a gestão pública e os representantes dos agricultores familiares para execução das etapas do Programa. Silva (2014) aponta que a falta de diálogo entre os atores envolvidos na implementação das políticas públicas é um dos principais fatores limitantes para o alcance da efetividade delas.

Em Belo Horizonte, para a formação dos preços de referência, constitui-se o "GT Preços", no qual a prefeitura contrata uma empresa terceirizada para realizar as cotações em mercados atacadistas, podendo não considerar os valores praticados pela agricultura familiar, o que pode vir a prejudicar o preço médio designado para os alimentos a serem comprados. No entanto, tal fato é embasado na Resolução n. 4 de 2015 do FNDE, que não define como uma obrigatoriedade a pesquisa de preços praticados pela agricultura familiar em outros mercados 5 .

Em alguns casos, como destaca Freitas e Freitas (2020), é possível que as próprias organizações da agricultura familiar sejam atores protagonistas para a implementação de políticas que favoreçam o setor, embora existam aquelas que ficam subordinadas às determinações e às orientações dadas pela prefeitura, limitando seu potencial de atuação. Conforme os

\footnotetext{
${ }^{5}$ Art. 29. O preço de aquisição dos gêneros alimentícios será determinado pela EEx., com base na realização de pesquisa de preços de mercado. $\S 1^{\circ} \mathrm{O}$ preço de aquisição será o preço médio pesquisado por, no mínimo, três mercados em âmbito local, priorizando a feira do produtor da agricultura familiar, quando houver acrescido dos insumos exigidos no edital de Chamada Pública, tais como despesas com frete, embalagens, encargos e quaisquer outros necessários para o fornecimento do produto (Brasil, 2015).
} 
relatos apresentados neste estudo, as organizações da agricultura familiar possuem certa legitimidade perante a Administração Pública e os agricultores. Como é relatado em Uberlândia, a proximidade entre a prefeitura e as organizações cooperativas da agricultura familiar tornou-se algo necessário e importante para que se pudesse pensar na operacionalização eficiente do PNAE no município.

Os representantes das cooperativas do município de Uberlândia relatam que participam do processo de construção das Chamadas Públicas e dos preços, uma espécie de acordo normativo informal estabelecido entre Administração Pública e cooperativas. O processo de compra é descentralizado, com a participação ativa dos agricultores familiares, principalmente para construção das Chamadas Públicas e dos cardápios. Nesse município, de acordo com relato do entrevistado G4, é realizado um levantamento da sazonalidade dos produtos regionais, da definição de preços, apresentando orçamentos com os preços praticados pelas cooperativas, e das discussões para substituição de produtos quando necessário, conforme determinado na Resolução do FNDE n. ${ }^{\circ} 4$ de 2015 (Brasil, 2015). Neste caso, atende-se um pressuposto apontado por Oliveira, Priore \& Siqueira (2021) como essencial para execução do PNAE, o envolvimento e a participação dos atores sociais na construção das Chamadas Públicas, tornando-as mais adequadas ao território e aos agricultores familiares e suas organizações.

Em Uberlândia, a Diretoria de Segurança Alimentar, pertencente à Secretaria de Agropecuária e Abastecimento, é o principal setor para a realização das compras de alimentos, enquanto a Secretaria de Educação trabalha com o acompanhamento nutricional nas escolas e na elaboração de cardápios. Como esse município possui um Programa Municipal de Segurança Alimentar e Nutricional, respaldado pelo Decreto Municipal n. ${ }^{\circ}$ 12.792/2011 (Uberlândia, 2011), é uma de suas competências apoiar a agricultura familiar, a fim de adquirir seus produtos para o abastecimento da alimentação escolar, entidades assistenciais e outros.

Em Belo Horizonte, também se institucionalizou a criação da Subsecretaria de Segurança Alimentar e Nutricional, inserida dentro da Secretaria de Assistência Social, Segurança Alimentar e Cidadania. A Subsecretaria é o principal setor da prefeitura responsável pela execução do PNAE, sendo sua competência instituir normas técnicas, gerenciar e prestar contas do Programa, além da elaboração dos cardápios. Ademais, o município determinou a Portaria Conjunta SMGO/SMPS/SMASAN/SMED ${ }^{6}$ n. ${ }^{\circ} 13$ de 2016, que determina as atribuições e responsabilidades para a execução do PNAE (Belo Horizonte, 2016), e a Lei Municipal n. ${ }^{\circ}$ 11.198/2019, criando o Programa Municipal de Alimentação Escolar (Belo Horizonte, 2019), assim como ocorreu em Uberlândia.

Essa Portaria Conjunta apresenta as diretrizes, o público atendido e demais determinações complementares ao PNAE, inclusive reforça a necessidade de estimular o desenvolvimento local sustentável, com incentivos para a aquisição de gêneros alimentícios diversificados, produzidos pelos agricultores familiares, preferencialmente em âmbito local, com prioridade aos produtores e empreendedores dos assentamentos da reforma agrária, comunidades tradicionais, indígenas e quilombolas.

Em Belo Horizonte, em decorrência da dificuldade de aquisição de produção local, devido a inexistência de área e população rural, a prefeitura determinou a Nota Técnica n. ${ }^{\circ}$ 01/2018 (Belo Horizonte, 2018), com o objetivo de avaliar a viabilidade da inclusão da Região Metropolitana (RMBH) como critério de priorização territorial no âmbito de compras da agricultura familiar. Trata-se da ampliação na caracterização dos fornecedores locais: de "fornecedores locais do município" para somente "fornecedores locais". Dessa forma, aprovado pela autarquia federal, houve a alteração dos critérios de prioridade local.

Ainda em relação às regras de priorização, em Governador Valadares, a secretaria responsável atende ao exposto na legislação sobre regras de priorização de grupos/categorias específicas. Contudo, nota-se uma interferência da gestão pública em garantir que não haverá grupos prioritários, colocando todos os produtores "num mesmo patamar" (Entrevistado G1, 2019).

${ }^{6}$ SMGO - Secretaria Municipal de Governo; SMPS - Secretaria Municipal de Políticas Sociais; SMASAN - Secretaria Municipal Adjunta de Segurança Alimentar e Nutricional; SMED - Secretaria Municipal de Educação. 
A Administração Pública municipal estimula os agricultores familiares a pertencerem a uma organização formal coletiva, cuja constituição é auxiliada por membros da gestão pública. Entretanto, tal determinação não é uma regra formalizada, mas é aceita pelos membros das associações.

Com relação aos dispositivos institucionais classificados como autorregulação das cooperativas e associações, notouse que as próprias cooperativas definem regras para facilitar o acesso ao PNAE nos municípios. Na realidade dos municípios estudados nesta pesquisa, verifica-se que há institucionalização de dispositivos de autorregulação. Em todos os casos, as regras e as coerções são informais, não sendo registradas em estatutos e atas, apenas impostas por meio de acordos firmados, exigindo relações de confiança mútua e de proximidade entre os membros das organizações envolvidas.

No município de Uberlândia, por exemplo, existe diálogo entre as três cooperativas de agricultura familiar locais, as quais, desde 2018, estabeleceram um acordo informal a fim de evitar as disputas pelos mesmos produtos, incorrendo em Chamadas Públicas desertas ${ }^{7}$ em outros produtos. Comportamento notado também em Montes Claros, pois, conforme relatado pela entrevistada G3, os agricultores familiares chegam a um acordo para democratizar o acesso do maior número de organizações locais possível a uma mesma Chamada Pública.

No ambiente interno, as organizações também criam dispositivos classificados como acordos coletivos institucionais para atender ao PNAE. A classificação da tipologia de dispositivos de acordos coletivos ocorre, principalmente, por intermédio das regras informais. Santos (2020) já havia demonstrado em seu estudo que, de fato, para cumprir as regras e as exigências determinadas pelo PNAE, as cooperativas e as associações da agricultura familiar precisam criar seus próprios dispositivos informais, conforme apontado pelos representantes das Cooperativas $\mathrm{C} 6$ e C11, que citam a criação de regras relacionadas à triagem para imersão de novos cooperados e para cooperados que não cumprem os acordos e planejamentos de entregas.

Na cooperativa C6, a seleção é baseada na classificação do mel, sendo os produtores com o "mel mais limpo" escolhidos para compor o quadro social da cooperativa. No caso da C11, a cooperativa realiza uma seleção informal de novos cooperados para minimizar a perda de atratividade econômica dos cooperados inseridos há mais tempo, evitando, assim, incorporar novos cooperados que produzem alimentos similares aos ofertados em grande escala pelos antigos cooperados.

As cooperativas $\mathrm{C} 2$ e C8 determinam outras regras que estão diretamente ligadas ao atendimento do PNAE. Em ambos os casos, novos cooperados são admitidos somente mediante a apresentação da DAP física. Isso ocorre devido à regra de priorização definida pela Resolução do FNDE n. ${ }^{\circ}$ 26/2013 determinar que, havendo empate entre os grupos formais, será selecionada a organização com maior porcentagem de agricultores familiares no seu quadro de sócios, conforme extrato da DAP jurídica, que contém a composição do quadro social.

Na cooperativa C7, de acordo com seu representante, realiza-se a articulação de cooperados, a fim de incentivar a diversificação produtiva para que a organização consiga acessar um maior número de itens das Chamadas Públicas, evitando que ocorra um excesso de oferta de um número limitado de itens. Caso a oferta de um determinado item supere o planejamento inicial da cooperativa, há a devolução do excedente para os associados que excederam a cota prevista. O mesmo procedimento ocorre nas cooperativas $\mathrm{C} 1$ e $\mathrm{C} 8$.

Ainda com relação aos acordos coletivos, os entrevistados das cooperativas C1 e C8 explicam que as suas respectivas cooperativas aplicam coerções informais aos cooperados que não cumprem as especificidades de qualidade e quantidade determinadas pela cooperativa. Os produtos que não atendem aos padrões estabelecidos são devolvidos aos associados e, caso a gestão das organizações avalie como necessário, o agricultor poderá sofrer punições: nos próximos planejamentos de entrega, pode haver a redução do limite de produtos que ainda serão entregues para aqueles que não cumprem tal determinação. $\mathrm{O}$ entrevistado C8 relata que a qualidade é o aspecto essencial: "se produto que for ruim volta para trás, o produtor fica no

\footnotetext{
${ }^{7}$ Segundo os gestores públicos entrevistados a "Chamada Pública deserta" é o termo utilizado para se referir ao desinteresse ou à inaptidão dos agricultores familiares ou suas organizações coletivas nos itens determinados pela Chamada.
} 
prejuízo".

Analisando sistematicamente a utilização das normas formais, informais e a aplicação de ambos os tipos de dispositivos institucionais, propostas por North (1991), notou-se que, nos municípios Governador Valadares e Montes Claros, com os laços pessoais, baseados em acordos coletivos e de autorregulação, com a presença de laços de confiança e alto grau de proximidade dos atores, as restrições informais são essenciais para determinar os rumos da execução da Política Pública. Quando não é possível criar acordos informais, as regras formais são utilizadas para restringir comportamentos e mediar relações, como é o caso de Belo Horizonte. E em outros casos, é possível a aplicação das características, tanto dos dispositivos formais, quanto dos informais, como é o caso de Uberlândia. Por sua vez, em Juiz Fora, a ausência de diálogo e de dispositivos institucionais específicos para o contexto local são fatores que dificultam a execução do Programa, principalmente considerando as compras da agricultura familiar que não ultrapassaram $12 \%$, nos anos analisados.

A partir dos relatos dos entrevistados, analisados com base na ótica institucionalista, fica evidente que, em alguns dos municípios estudados, há maior destaque e envolvimento dos agricultores familiares na execução do PNAE. Em outros casos, as ações, regras e procedimentos são determinados pela Administração Pública e aceitos pelos agricultores e suas cooperativas e associações. Entretanto, ainda não é possível afirmar, categoricamente, que, em determinado município, os protagonistas do PNAE são atores da agricultura familiar e suas organizações coletivas, pois, apesar de ter sido relatado proximidade entre a Administração Pública e as cooperativas e associações em Governador Valadares, Uberlândia e Montes Claros, por exemplo, ainda se percebe dependência do apoio dos gestores públicos às organizações econômicas.

\section{Considerações Finais}

Este estudo garantiu suporte à compreensão de que dois dos municípios de maior porte, Belo Horizonte e Uberlândia, possuem maiores níveis de institucionalização formal, uma vez que são os municípios que mais criaram dispositivos institucionais complementares para execução do PNAE (normas e diretrizes, por meio de resoluções, portarias e leis municipais). Essa inclusão de orientações modifica o desenho institucional e cria características ainda mais específicas, se comparado aos municípios que seguem somente as determinações expostas na legislação federal. Entretanto, não é possível afirmar que os maiores níveis de institucionalização formal estão diretamente relacionados à eficiência do PNAE, pois, apesar de haver dispositivos institucionais nesses municípios, em nenhum dos anos analisados adquiriu-se $30 \%$ dos produtos da agricultura familiar.

Nos municípios de médio porte, Governador Valadares e Montes Claros, percebe-se maior proximidade entre os agricultores, os gestores públicos locais e os representantes das cooperativas e associações, o que demonstra maiores níveis de relações interpessoais entre os agentes executores da política no âmbito local. Além disso, são os municípios que se destacam no quesito determinações informais (acordos e regras informais definidos entre gestores e representantes da agricultura familiar), diminuindo a institucionalização de acordos formalizados.

O outro município de grande porte, Juiz de Fora, encontra ainda mais dificuldade em comprar produtos da agricultura familiar. Não há institucionalização de regras formais e falta diálogo entre a prefeitura e as organizações coletivas do município. Como foi relatado, há um distanciamento entre quem compra e quem produz, não havendo consulta aos agricultores quanto aos produtos, à sazonalidade e aos preços praticados em outros mercados.

Os municípios com maiores níveis de participação social são Uberlândia e Montes Claros, que também possuem maiores níveis de satisfação dos agricultores familiares, principalmente em relação aos preços e à forma como a Administração Pública executa o PNAE, visto que estão imersos nesse processo. O estímulo e a aproximação da gestão pública com as cooperativas e associações torna-se parte importante do processo de implementação e aumenta a confiança no trabalho desenvolvido pelas secretarias, possibilitando alcançar êxito na operacionalização do Programa. Assim, os agricultores passam 
de meros fornecedores a coexecutores no processo de compra e venda, em uma relação de construção conjunta durante as etapas.

Um aspecto observado na implementação é a dificuldade de institucionalizar regras, principalmente formais, que facilitem a articulação entre as secretarias municipais e os agricultores familiares. Com base nas discussões deste trabalho, percebe-se a necessidade de criação de inovações institucionais e de políticas públicas, a fim de impulsionar a produção de alimentos de qualidade e em quantidade suficiente para atender ao mercado institucional. Entendendo que tais ações garantem a promoção do desenvolvimento local, por meio do aumento de renda gerado às famílias e, consequentemente, do consumo local.

Considerando a carência de estudos sobre os dispositivos institucionais determinados no âmbito local, para trabalhos futuros, sugere-se analisar a implementação do PNAE em outros municípios, especialmente de grande e médio porte, de outros estados brasileiros, buscando compreender as institucionalidades criadas em diferentes contextos sociais e relacionais. Sugerese também estudos futuros que retratem os impactos causados pela Pandemia da Covid-19 na operacionalização do PNAE e nos dispositivos institucionais dos municípios, compreendendo as estratégias adotadas pelas prefeituras para executar o Programa durante a paralisação das aulas.

\section{Agradecimentos}

Agradecimento ao Conselho Nacional de Desenvolvimento Científico e Tecnológico (CNPq) por financiar a pesquisa que originou este artigo.

\section{Referências}

Barrett, S. (2004). Implementation Studies: Time for a Revival? Personal Reflections on 20 Years of Implementation Studies. Public Administration, 82(2), 249-262. https://doi.org/10.1111/j.0033-3298.2004.00393.x.

Belo Horizonte (2016). Portaria Conjunta SMGO/SMPS/SMASAN/SMED n. ${ }^{\circ} 13$ de 2016, que determina as atribuições e responsabilidades para a execução do PNAE.

Belo Horizonte (2018). Nota Técnica COMPRAS/DFAB/SUSAN N ${ }^{\circ}$ 01/2018. Analisa os critérios de priorização de propostas no âmbito dos chamamentos públicos de credenciamento de Organizações Formais de Agricultores e Agricultoras Familiares para aquisição de gêneros alimentícios da agricultura familiar destinados à execução do Programa Nacional de Alimentação Escolar (PNAE).

Belo Horizonte (2019). Lei Municipal n.o 11.198/2019. <https://leismunicipais.com.br/a/mg/b/belo-horizonte/lei-ordinaria/2019/1120/11198/lei-ordinaria-n11198-2019-institui-o-programa-municipal-de-alimentacao-escolar-de-belo-horizonte-e-da-outras-providencias>

Bonduki, M. R. P. C. (2017). Entre chicotes e cenouras orgânicas: cooperação, coerção e coordenação na implementação das compras da agricultura familiar para o PNAE. (Dissertação de mestrado, Fundação Getúlio Vargas, São Paulo, Brasil). Recuperado de https://bibliotecadigital.fgv.br/dspace/handle/10438/18 222.

Brasil. (2009). Lei 11.947 de 16 de junho de 2009. Dispõe sobre o atendimento da alimentação escolar e do Programa Dinheiro Direto na Escola aos alunos da educação básica. http://www.planalto.gov.br/ccivil_03/_ato2007-2010/2009/lei/111947.htm.

Brasil. (2013). Resolução CD/FNDE n 26, de 17 de junho de 2013. Dispõe sobre o atendimento da alimentação escolar aos alunos da educação básica no âmbito do Programa Nacional de Alimentação Escolar - PNAE. < https://www.fnde.gov.br/acesso-a-informacao/institucional/ legislacao/item/4620-resolu\%C3\%A7\%C3\%A3o-cd-fnde-n\%C2\%BA-26,-de-17-de-junho-de-2013>.

Brasil. (2015). Resolução CD/FNDE nº 4, de 2 de abril de 2015. Altera a redação dos artigos 25 a 32 da Resolução/CD/FNDE nº 26 , de 17 de junho de 2013, no âmbito do Programa Nacional de Alimentação Escolar (PNAE). <http://www.gestaoescolar.diaadia.pr.gov.br/arquivos/File/alimenatacao _escolar/resolucao042015_ceae.pdf>.

Brasil. (2021). Ministério do Desenvolvimento Social. Marco de Referência de Educação Alimentar e Nutricional para as Políticas Públicas. CAISAN. <http://mds.gov.br/caisan-mds/educacao-alimentar-e-nutricional/marco-de-referencia-de-educacao-alimentar-e-nutricional-para-as-politicaspublicas〉.

Carvalho, C. A. P, Vieira, M. M. F, \& Lopes, F, D. (1999). Contribuições da perspectiva institucional para análise das organizações. In: Encontro Anual da Associação Nacional de Pós-Graduação em Administração. Foz do Iguaçu. http://www.anpad.org.br/admin/pdf/enanpad1999-org-26.pdf.

Costa, B. A. L., Amorim Junior, P. C. G., \& Silva, M. G. da. (2015). As Cooperativas de Agricultura Familiar e o Mercado de Compras Governamentais em Minas Gerais. Revista de Economia e Sociologia Rural, 53(1), 109-126. https://doi.org/10.1590/1234-56781806-9479005301006. 
Dimaggio. P. J., \& Powell. W. W. (1999). Introducción. In: W. W, Dimaggio. P. J, Powell (Eds), El Nuevo Instutcionalismo en el análisis organizacional. Fondo de Cultura Económica, 33-75.

Fundo Nacional de Desenvolvimento da Educação (FNDE). (2021). Caderno de Legislação 2021. https://www.fnde.gov.br/index.php/centrais-deconteudos/publicacoes/category/116-alimentacao-escolar?download=12530: caderno-de-legisla\%C3\%A7\%C3\%A3o-2021

Fundo Nacional de Desenvolvimento da Educação (FNDE). (2021). Sistema de gestão de Prestação de contas do Fundo Nacional de Desenvolvimento da Educação. SIGPC. https://www.fnde.gov.br/sigpcadm/sistema.pu?operation=localizar.

Freitas, A. F. (2015). Dinâmicas sociais e desenvolvimento territorial no território Serra do Brigadeiro: atores, redes e instituições. (Tese de doutorado, Universidade Federal de Minas Gerais, Belo Horizonte, Brasil). https://repositorio.ufmg.br/handle/1843/BUBD-9WVHMH.

Freitas, A. F. (2017). Dinâmicas locais de implementação do Programa Nacional de Alimentação Escolar. (Tese de doutorado, Universidade Federal de Viçosa, Brasil). https://www.locus.ufv.br/handle/123456789/11570.

Freitas, A. F., \& Freitas, A. F. (2020). Análise relacional do Programa Nacional de Alimentação Escolar: relevando dimensões institucionais dos processos locais de implementação. Sociedade e Estado, 35 (2), 525-552. https://doi.org/10.1590/s0102-6992-202035020007.

Grisa, C. \& Schineider, S. (2014). Três gerações de políticas públicas para agricultura familiar e interação entre Estado e Sociedade Civil no Brasil. RESR, 52(suppl 1), 125-146. https://doi.org/10.1590/S0103-20032014000600007.

Howlett, M., Ramesh, M. \& Perl, A. (2009). Studying Public Policy: Policy Cycles and Policy Subsystems. Oxford University Press.

Instituto Brasileiro de Geografia e Estatística. (2018). Regiões de influência das cidades. https://biblioteca.ibge.gov.br/visualizacao/livros/liv101728.pdf.

Jepperson, R. L. (1999). Instituciones, efectos institucionales e institucionalismo. In Powell, W.W \& Dimaggio, P.J (Eds), El Nuevo Instutcionalismo en el análisis organizacional. Fondo de Cultura Económica, pp 193 -215.

Lipsky, M. (2010). Street-level bureaucracy: dilemmas of the individual in public service. Russell Sage Foundation.

Lotta, G. S. (2010). Implementação de políticas públicas: o impacto dos fatores relacionais e organizacionais sobre a atuação dos burocratas de nível da rua no Programa Saúde da Família. (Tese de doutorado, Universidade de São Paulo, São Paulo, Brasil). https://www.teses.usp.br/teses/disponiveis/8/8131/tde20102010-120342/publico/2010_GabrielaSpangheroLotta.pdf.

March, J. G. \& Olsen, J. P. (1984). The New Institutionalism: Organizational Factors in Political Life. American Political Science Association, 78(3), 734-749.

Marconi, M. A., \& Lakatos, E. M. (2007). Técnicas de pesquisa. Editora Atlas.

Marques, E. (2013). As políticas públicas na Ciência Política. In: Marques, E, Faria, C. A. P. (Eds.). A política pública como campo multidisciplinar. Ed. Editora Fiocruz/ Editora Unesp, 23-46.

Minayo, M. C. S. (2009) Pesquisa Social: teoria, método e criatividade. Editora Vozes.

Moura, J. V. (2014). Ambiente político e tecido social no Programa Nacional de Alimentação Escolar (PNAE) no Território Mato Grande/RN. Revista Política e Planejamento Regional, 1 (2), 189- 210. Recuperado de http://www.revistappr.com.br/artigos/publicados/Ambiente-politico-e-tecido-social-no-ProgramaNacional-de-Alimentacao-Escolar-(PNAE)-no-Territorio-Mato-GrandeRN.pdf.

North, D. C. (1991). Institutions. The Journal of Economic Perspectives, 5(1), 97-112. 10.1257/jep.5.1.97.

Oliveira, C. B., Priore, S. E., \& Siqueira, R. L. (2021). Análise da inserção de agricultores familiares prioritários nas chamadas públicas da alimentação escolar. Research, Society and Development, 10(4), 1-14. http://dx.doi.org/10.33448/rsd-v10i4.14028.

Pegolo, G. E \& Silva, M. V. (2010). Consumo de energia e nutrientes e a adesão ao Programa Nacional de Alimentação Escolar (PNAE) por escolares de um município paulista. Segurança Alimentar Nutricional, 17(2), 50-62. https://doi.org/10.20396/san.v17i2.8634792.

Peixinho, A. M. L. (2013). A trajetória do Programa Nacional de Alimentação Escolar no período de 2003-2010: relato do gestor nacional. Ciência \& Saúde Coletiva, 18, (4), 909-916. https://doi.org/10.1590/S1413-81232013000400002.

Prado, T. R, et al. (2013). Agricultura familiar na alimentação escolar: estudo de caso em dois municípios de Minas Gerais. Nutrire. 38(3), 256-268. http://dx.doi.org/10.4322/nutrire.2013.024.

Santos, L. F. (2020). Implementação do Programa Nacional de Alimentação Escolar (PNAE) pela agricultura familiar: quadro teórico-analítico e evidências empíricas em territórios rurais. (Tese de doutorado, Universidade Federal do Rio Grande do Norte, Rio Grande do Norte, Brasil). https://reposi torio.ufrn.br/jspui/handle/123456789/29317.

Saraiva, E. B. et al. (2013), Panorama da compra de alimentos da agricultura familiar para o Programa Nacional de Alimentação Escolar. Ciência \& Saúde Coletiva, 18(4), 927-935. https://doi.org/10.1590/S1413-81232013000400004.

Schmitt, C. J. (2011). Redes, atores e desenvolvimento rural: perspectivas na construção de uma abordagem relacional. (2011). Sociologias, 13(7), 82-112. https://doi.org/10.1590/S1517-45222011000200005.

Silva, D. W. (2015). Produzindo prerrogativas de cidadania: o acesso da agricultura familiar à política de fornecimento de produtos para a alimentação escolar. (Tese de doutorado, Universidade Federal do Rio Grande do Sul, Rio Grande do Sul, Brasil). https://lume.ufrgs.br/handle/10183/147454.

Silva, M. G, Dias, M. M. \& Amorim Junior, P. C. G. (2015). Mudanças Organizacionais em Empreendimentos de Agricultura Familiar a partir do Acesso ao Programa Nacional de Alimentação Escolar. Revista de Economia e Sociologia Rural, 53(2), 289-304. https://doi.org/10.1590/1234-567818069479005302006. 
Research, Society and Development, v. 10, n. 10, e363101018673, 2021

(CC BY 4.0) | ISSN 2525-3409 | DOI: http://dx.doi.org/10.33448/rsd-v10i10.18673

Silva, S. P. (2014). Mediação social e incidência territorial de políticas públicas de desenvolvimento rural no Médio Jequitinhonha/MG. Cadernos Gestão Pública e Cidadania, 19 (65). 164-185. https://doi.org/10.12660/cgpc.v19n65.9145.

Silva, S. P. (2019). Trajetória e padrões de mudança Institucional no Programa Nacional de Alimentação Escolar. Ipea, Texto para discussão TD 2529. https://www.ipea.gov.br/portal/index.php?option=com_content\&view=article\&id=35224.

Silva, S. R. (2015). Programa Nacional de Alimentação Escolar: análise da implementação no município de Belo Horizonte - MG. (Dissertação de mestrado, Universidade Federal de Viçosa, Viçosa, Brasil). https://www.locus.ufv.br/handle/123456789/7587.

Siqueira, R. L. et al. (2014). Análise da incorporação da perspectiva do direito humano à alimentação adequada no desenho institucional do Programa Nacional de Alimentação Escolar. Ciência \& Saúde Coletiva, 19(1), 301-310. https://doi.org/10.1590/1413-81232014191.2114.

Stamm, C., et al. (2013). A população urbana e a difusão das cidades de porte médio no Brasil. Interações, 14(2), 251-265. https://doi.org/10.1590/S151870122013000200011

Uberlândia (2011). Decreto Municipal n. ${ }^{\circ}$ 12.792/2011. <https://leismunicipais.com.br/a1/mg/u/uberlandia/decreto/2011/1279/12792/decreto-n-12792-2011dispoe-acerca-do-programa-municipal-de-seguranca-alimentar-e-nutricional-no-municipio-de-uberlandia-e-da-outras-providencias>

Vergara, S. C. (2010). Projetos e relatórios de pesquisa em administração. Editora Atlas.

Yin, R. K. (2005). Estudo de caso: planejamento e métodos. Bookman. 